\title{
Erratum to: How to justify beliefs about the future - some epistemological remarks
}

\author{
Matthias Sonk ${ }^{1}$
}

Published online: 7 June 2016

(C) The Author(s) 2016. This article is published with open access at Springerlink.com

Erratum to: Eur J Futures Res (2015) 3:17

DOI 10.1007/s40309-015-0076-7

Due to technical problems during correction of the paper some minor errors occurred:

On page 2 of 6 , in chapter "The basics of thoughts concerning the future" in two logical expressions there is a

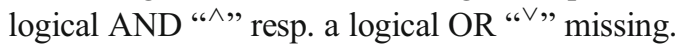

Instead of " $(\forall x \neg(x \neg x))$ " it should read " $\left(\forall x \neg\left(x^{\wedge} \neg x\right)\right)$ " and instead of " $(\forall \mathrm{x}(\mathrm{x} \neg \mathrm{x}))$ " it should read " $\left(\forall \mathrm{x}\left(\mathrm{x}^{\vee} \neg \mathrm{x}\right)\right)$ ". These mistakes are in the PDF only

In the abstract several hyphenations can be found which are not correct in these places, i.e. logi-cal (row 2 in the PDF), unam-biguous (row 13 in the PDF) and Re-garding (row 15 in the PDF).

There is also another mistake (row 15 of the PDF) of the abstract: "internalsim" should of course be "internalism".

These mistakes showed up in the HTML-version as well.

Open Access This article is distributed under the terms of the Creative Commons Attribution 4.0 International License (http:// creativecommons.org/licenses/by/4.0/), which permits unrestricted use, distribution, and reproduction in any medium, provided you give appropriate credit to the original author(s) and the source, provide a link to the Creative Commons license, and indicate if changes were made.

The online version of the original article can be found at http://dx.doi.org/ 10.1007/s40309-015-0076-7.

Matthias Sonk

matthiassonk@zedat.fu-berlin.de

1 Freie Universität Berlin, Kaiserswerther Str. 16-18,

14195 Berlin, Germany 